\title{
Biphasic kinetics of peripheral blood T cells after triple combination therapy in HIV-1 infection: A composite of redistribution and proliferation
}

\author{
Nadine G. Pakker ${ }^{1,2}$, Daan W. Notermans ${ }^{3}$, Rob J. de Boer ${ }^{4}$, Marijke T.L. Roos ${ }^{1,2}$, \\ Frank de Wolf ${ }^{5}$, Andrew Hil. ${ }^{6}$, John M. Leonard ${ }^{7}$, SVEn A. Danner ${ }^{3,8}$, \\ Frank Miedema ${ }^{1,2,5}$ \& Peter T.A. SChellekens ${ }^{1,2,8}$ \\ 'Department of Clinical Viro-Immunology, Central Laboratory of the Netherlands Red Cross \\ Blood Transfusion Service, Plesmanlaan 125, 1066 CX Amsterdam, The Netherlands \\ ${ }^{2}$ Laboratory for Experimental and Clinical Immunology, ${ }^{3}$ Division of Infectious Diseases, Tropical Medicine and \\ AIDS and National AIDS Therapy Evaluation Center, 'Department of Human Retrovirology, \\ ${ }^{8}$ Department of Internal Medicine, Academic Medical Center, University of Amsterdam, \\ Meibergdreef 15, 1105 AZ Amsterdam, The Netherlands \\ ${ }^{4}$ Theoretical Biology, Utrecht University, Padualaan 8, 3584 CH Utrecht, The Netherlands

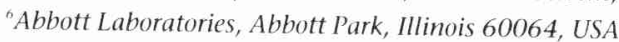 \\ Glaxo-Wellcome Research and Development, Greenford-Middlesex UB6 OHE, United Kingdom \\ Correspondence should be addressed to F.M.; e-mail: miedema@clb.nl
}

\begin{abstract}
The origin of $\mathrm{CD}^{+} \mathrm{T}$ cells reappearing in the blood following antiretroviral therapy in human immunodeficiency virus type-1 (HIV-1) infection is still controversial. Here we show, using mathematical modeling, that redistribution of $\mathrm{T}$ cells to the blood can explain the striking correlation between the initial $\mathrm{CD}^{+}$and $\mathrm{CD}^{+}$memory $\mathrm{T}$-cell repopulation and the observation that 3 weeks after the start of treatment memory $\mathrm{CD4}^{+} \mathrm{T}$-cell numbers reach a plateau. The increase in $\mathrm{CD4} 4^{+} \mathrm{T}$ cells following therapy most likely is a composite of initial redistribution, accompanied by a continuous slow repopulation with newly produced naive $\mathrm{T}$ cells.
\end{abstract}

Treatment of human immunodeficiency virus-type 1 (HIV-1)infected individuals with potent triple combinations of antiretroviral drugs results in a dramatic decline of the viral load to "undetectable" HIV-1 RNA levels in plasma and tissue in the majority of patients (R.M. Gulick et al., XI International Conference on AIDS, Vancouver, July 7-12, Abstr. Th.B.931; 1996; and refs. 1-4). Apart from controlling virus replication, the major goal of antiviral therapy is to achieve a degree of immune reconstitution. Although significant increases in $\mathrm{CD} 4^{+} \mathrm{T}$ cell numbers have been observed, the mechanisms of T-lymphocyte repopulation and restoration of immune function after sustained suppression of HIV replication is still unclear. Recent studies have provided evidence for a high turnover of $\mathrm{CD} 4^{+} \mathrm{T}$ cells driven by the large amounts of virus that are produced daily, suggesting physical exhaustion of $\mathrm{CD} 4^{+} \mathrm{T}$-cell renewal as a cause of $\mathrm{CD}^{+}{ }^{+} \mathrm{T}$-cell depletion ${ }^{5,6}$. If so, antiviral treatment, despite very efficient control of virus replication, could have its limit as to the restoration of the immune system. In the present study we sought to address this issue and studied in detail the kinetics and characteristics of immune reconstitution after triple combination therapy.

\section{Response to therapy}

Patient recruitment and study treatment were as previously described in detail ${ }^{4}$. Briefly, the study recruited 33 adults with documented HIV-1 infection and CD4+ T-lymphocyte counts of at least $50 \mathrm{cells} / \mu \mathrm{l}$, a plasma HIV RNA level of at least 30,000 copies $/ \mathrm{ml}$ and no prior treatment with antiretrovirals.
Patients were randomized to receive either immediate triple combination therapy with ritonavir $[600 \mathrm{mg}$ twice a day (BID)], zidovudine (ZDV) (300 mg BID) and lamivudine (3TC) (150 mg BID), or delayed triple therapy, that is, starting with ritonavir monotherapy, and 3 weeks later adding ZDV and 3TC. Baseline characteristics of patients are shown in Table 1. No significant differences in baseline values of the immunological and virological parameters were observed between the two treatment groups.

HIV-1 RNA levels in plasma decreased significantly over 36 weeks $(P<0.005)$ to levels below the quantification limit in a large majority of patients in both groups (Fig. 1e) ${ }^{4}$. During 36 weeks of follow-up, mean $\mathrm{CD} 4^{+} \mathrm{T}$-cell counts increased significantly in both groups $(P<0.005)$ (Fig. $1 a)$. At 36 weeks, the mean rise in the group receiving the triple combination therapy from the start of the study was $196 \mathrm{CD} 4^{+} \mathrm{T}$ cells per microliter blood (s.e.m. $43 \mathrm{CD}^{+}{ }^{+} \mathrm{T}$ cells $/ \mu \mathrm{l}$ ) and in the group with delayed triple therapy a rise of $145 \pm 33 \mathrm{CD} 4^{+} \mathrm{T}$ cells/ $\mu \mathrm{l}$ blood was observed. For the complete period of follow-up, no significant difference was observed between the two treatment groups in either $\mathrm{CD}^{+}{ }^{+} \mathrm{T}$-cell response or HIV RNA reduction. There was an increase in CD8 ${ }^{+} \mathrm{T}$-cell counts in the first two months of treatment $\left(214 \pm 67\right.$ and $400 \pm 144 \mathrm{CD} 8{ }^{+} \mathrm{T}$ cells $/ \mu \mathrm{l}$ blood for the early and delayed treatment groups, respectively), comparable with results from ritonavir monotherapy ${ }^{7}$; however, the absolute number of $\mathrm{CD}^{+} \mathrm{T}$ cells subsequently de-

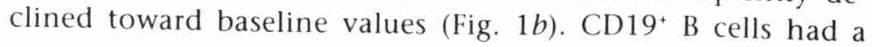
response similar to that observed for the CD4 $4^{+} \mathrm{T}$ cells (Fig. 1c). 
In parallel with the quantitative increase in T-cell numbers the in vitro proliferative response to CD3 monoclonal antibodies, expressed per $10^{1} \mathrm{CD}^{*} \mathrm{~T}$ cells, showed a sustained improvement to approximately $50 \%$ of normal responses (Fig. 1d).

\section{$\mathrm{CD}^{+}$and $\mathrm{CD}^{+}{ }^{+} \mathrm{T}$-cell recovery rates}

As treatment groups did not differ with regard to the pattern of T-cell recovery, we combined the data from both patient groups to analyze the kinetics of reappearing naive and memory T-cell subsets. T-cell subsets expressing CD45RA and CD62L are regarded as truly naive $\mathrm{T}$ cells, whereas $\mathrm{T}$ cells expressing CD45RO and T cells that express CD45RA but lack CD62L are regarded as memory lymphocytes ${ }^{8,9}$. For one representative, well-responding patient, flow cytometric images of CD45RA and CD62L staining are plotted at three different time points during followup (Fig. 2). The patterns for recovery of naive and memory $\mathrm{CD}^{+}$and $\mathrm{CD}^{+} \mathrm{T}$ cells in the total study population are depicted in Fig. $3, a$ and $b$.

Both the $\mathrm{CD}^{+}$and $\mathrm{CD} 8^{+}$recovery rates seem to be biphasic. For the $\mathrm{CD} 4^{+} \mathrm{T}$ cells the most rapid recovery occurs during the first three weeks, whereas rapid CD8+ T-cell recovery is observed within the first six weeks. The individual T-cell recovery rates of all patients over the entire period of follow-up, and over the rapid and slow phases separately, were estimated by linear regression (Table 2). Calculating the total-body production over the initial period, we found a daily increase of $1.3 \times 10^{9} \mathrm{CD} 4^{+} \mathrm{T}$ cells, in agreement with earlier findings ${ }^{5,6,10}$, and $2.1 \times 10^{\circ} \mathrm{CD}^{+} \mathrm{T}$ cells. The average exponential growth rates over this period were
Table 1 Description of baseline characteristics

\begin{tabular}{|c|c|c|c|c|}
\hline \multicolumn{5}{|l|}{ No. of participants } \\
\hline Male/female & \multicolumn{2}{|l|}{$16 / 1$} & \multicolumn{2}{|l|}{$15 / 1$} \\
\hline Age (years) ${ }^{\mathrm{b}}$ & 38 & $(26-57)$ & 39 & $(26-61)$ \\
\hline \multicolumn{5}{|l|}{ CDC class at entry } \\
\hline A & \multicolumn{2}{|l|}{6} & \multicolumn{2}{|l|}{8} \\
\hline B & \multicolumn{2}{|l|}{7} & \multicolumn{2}{|l|}{5} \\
\hline C & \multicolumn{2}{|l|}{4} & \multicolumn{2}{|l|}{3} \\
\hline \multicolumn{5}{|l|}{ Tlymphocytes $(\text { cells } / \mu l)^{b}$} \\
\hline CD4 ${ }^{+} \mathrm{T}$ cells & 177 & $(40-403)$ & 134 & $(37-600)$ \\
\hline CD8 ${ }^{+} T$ cells & 1027 & $(273-1777)$ & 927 & $(320-2277)$ \\
\hline $\mathrm{CD}^{+} / \mathrm{CD} 8^{*} \mathrm{~T}$-cell ratio & 0.18 & $(0.09-0.68)$ & 0.16 & $(0.06-0.60)$ \\
\hline \multicolumn{5}{|l|}{$\begin{array}{l}\text { T-cell proliferative response } \\
\text { (c.p.m. } / 10^{3} T \text { cells) }\end{array}$} \\
\hline CD3 mAb & 34 & $(3-260)$ & 25 & $(4-258)$ \\
\hline \multicolumn{5}{|l|}{ Viral load (log copies $/ \mathrm{ml})^{b}$} \\
\hline Plasma RNA levels & 5.27 & $(4.59-6.36)$ & 5.37 & $(4.50-5.92)$ \\
\hline \multicolumn{5}{|l|}{ Phenotype } \\
\hline $\mathrm{NSI} / \mathrm{SI}$ & $11 / 6$ & & $11 / 5$ & \\
\hline
\end{tabular}

'The immediate triple (early treatment) started with ritonavir, ZDV and 3TC simultaneously, the delayed triple started with ritonavir and added 3 weeks later ZDV and 3TC.

Median values ( 5 and 95 percentile).

'According the 1993 revised AIDS definition"

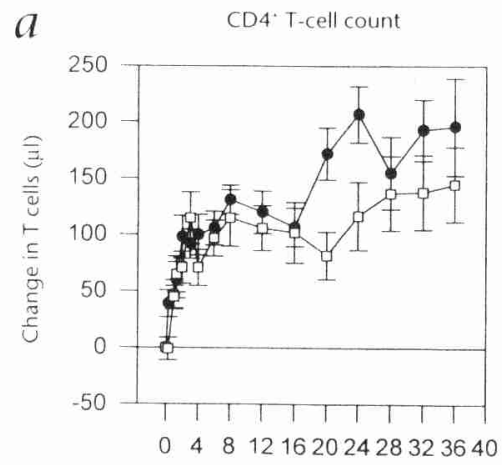

Time from start of treatment (weeks)

Fig. 1 Peripheral blood CD4 and CD8 T-cell numbers, improvement of $\mathrm{T}$-cell function in vitro, and HIV-1 RNA load. The immediate triple treatment (-) started with ritonavir, ZDV and 3TC simultaneously, the delayed triple therapy ( $\square$ ) started with ritonavir and added ZDV and 3TC three weeks later. $\boldsymbol{a}$, Mean change from baseline of CD4* T-lymphocyte numbers $\boldsymbol{b}$, Mean change from baseline of $\mathrm{CD} 8^{+}$T-lymphocyte numbers. c. Mean change from baseline of CD19' B-lymphocyte numbers. $\boldsymbol{d}$, Mean change from baseline in proliferative response per $10^{3} \mathrm{~T}$ cells after stimulation with CD3 mAb.e, Mean change from baseline of plasma HIV-1 RNA levels. Bars represent s.e.m.
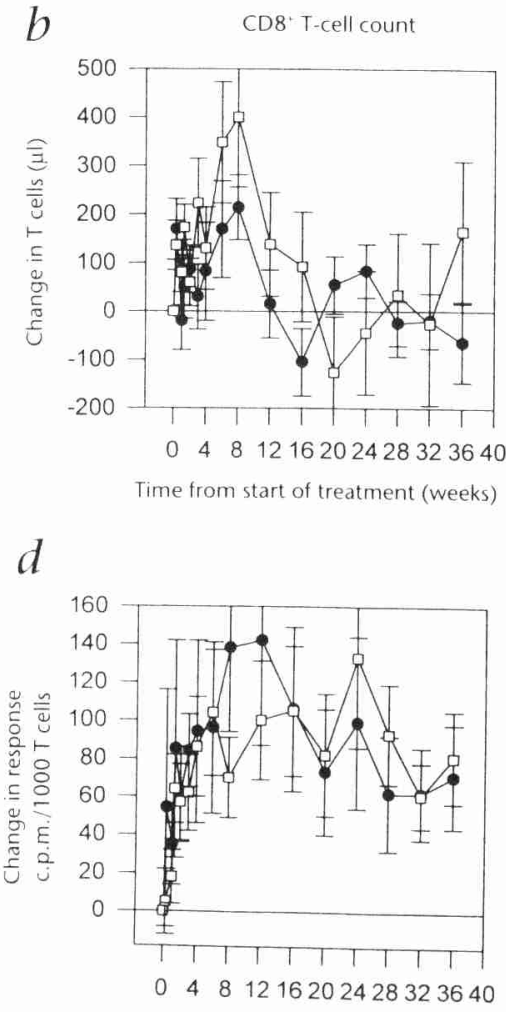

Time from start of treatment (weeks)

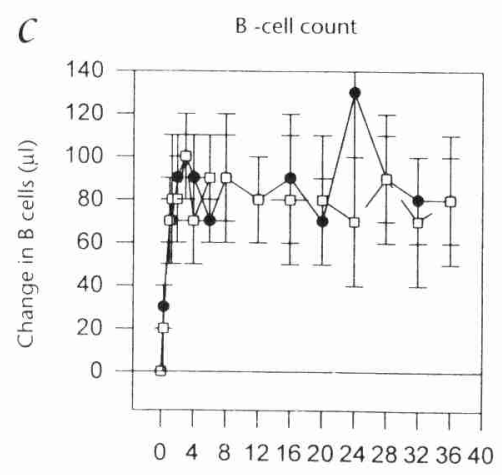

Time from start of treatment (weeks)

$e$

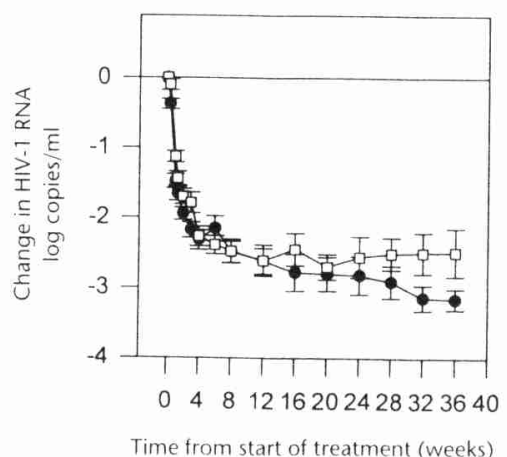


growth rates differ by a factor of two (0.015/day and 0.03/day, respectively). For the $\mathrm{CD}^{+}$cells they are approximately the same (0.011/day and $0.007 /$ day, respectively). The early fast recovery of CD $4^{+} \mathrm{T}$ cells is similar to the estimated total $\mathrm{CD} 4^{+}$T-cell recovery reported in earlier studies ${ }^{5,6}$, which suggests that the latter also largely resulted from memory $\mathrm{T}$ cell recovery in the blood.

During the subsequent slow recovery period, the total CD4+ T-cell production slowed down to $10^{8} \mathrm{CD}^{+} \mathrm{T}$ cells per day, which is largely explained by production of naive $\mathrm{T}$ cells (Table $2 a$ ). For naive $\mathrm{CD}^{+} \mathrm{T}$ cells we found no significant difference in the early and late production rates $(P=0.07)$, hence on average the naive $\mathrm{CD}_{4}{ }^{+} \mathrm{T}$-cell recovery rate over the entire period was $5.7 \times 10^{7}$ cells/day. This is in agreement with preliminary observations in a monotherapy trial with ritonavir, which also reported slow kinetics of naive CI) $4^{+} \mathrm{T}$ cells $\mathrm{s}^{7}$. In contrast, the recovery rates of the memory CD4 $4^{+} \mathrm{T}$ cells in the early and late periods are significantly different $(P<0.005)$ and drop from $10^{9}$ cells/day to virtually zero. Although the early $\mathrm{CD}^{+}{ }^{+} \mathrm{T}$-cell recovery resembles that of the $\mathrm{CD}^{+} \mathrm{T}$ cells, total $\mathrm{CD}^{+}$ counts decline during the late phase. This can be explained by a diminishing antigenic stimulation once the HIV-1 viral load levels have dropped significantly. The CD8 ${ }^{+} \mathrm{T}$-cell response will not only involve HIV-1-specific cells, but also nonspecific $\mathrm{CD}^{+} \mathrm{T}$ cells, activated as bystander cells stimulated by cytokines ${ }^{11,12}$. Indeed most of the decline in CD $8{ }^{+}$cells is caused by a drop in memory cells (Table $2 b$ ). In fact, kinetics of naive $C D 8^{+} \mathrm{T}$ cells resemble the kinetics of naive $\mathrm{CD}^{+} \mathrm{T}$ cells, with a steady increase on the order of $10^{8}$ cells/day over the entire period. Also CD $19^{+}$B cell numbers increase with strikingly similar kinetics as memory $\mathrm{CD}^{+}{ }^{+}$ T cells (Fig. 1C).

\section{Redistribution or proliferation}

There has been some debate as to the origin of the initial CD4 T-cell repopulation ${ }^{13,14}$. Originally it was argued that this fast repopulation reflects the pretreatment turnover of proliferating $\mathrm{CD}^{+}{ }^{+} \mathrm{T}$ cells during HIV-1 infection ${ }^{5,6}$. An important argument for such a high steady-state CD4+ T-cell production of $10^{9}$ cells/day was the observation that after treatment the exponential growth rate of the $\mathrm{CD} 4^{+} \mathrm{T}$ cells was inversely correlated with the baseline CD $4^{+} \mathrm{T}$-cell count. Such a CD $4^{+} \mathrm{T}$-cell density-dependent growth would account for a growth rate up to $0.08 /$ day at low CD $4^{+}$counts ${ }^{5}$. We find very similar "density-dependent" results for the recovery of memory CD $4^{+} \mathrm{T}$ cells, as depicted in Fig. $4 a$, also suggesting growth rates up to 0.1 day at low baseline CD $4^{+}$T-cell counts, and decreasing to virtually zero at CD $4+$ counts over 400 cells/ $\mu$ l. However, one finds a similar relation between the exponential growth rate of CD8 ${ }^{+}$memory $T$ cells and the baseline CD4+ count (Fig. 4b). Thus, surprisingly, the per capita $C D 8^{+}$recovery is higher in patients with lower $\mathrm{CD} 4^{+}$counts who have a more impaired immune function. The original hypothesis of a density dependent proliferation leaves unexplained why the reconstitution pattern of the memory CD8 ${ }^{+} \mathrm{T}$ cells is so similar to that of the memory $\mathrm{CD}^{+} \mathrm{T}$ cells.

This hypothesis also does not explain why $\mathrm{CD} 4^{+} \mathrm{T}$-cell repopulation is slowing down to $10^{8}$ cells/day during the second phase of T-cell recovery with a virtual lack of memory T-cell production. If during clinical latency large numbers of $\mathrm{CD} 4^{+} \mathrm{T}$ cells are produced on a daily basis as has been hypothesized ${ }^{5.6}$, one would expect the same production to continue during therapy until normal CD4+ $\mathrm{T}$-cell levels are reached.

It has been proposed that the initial $\mathrm{CD}^{+}{ }^{+} \mathrm{T}$-cell recovery results from redistribution of cells from the lymphoid tissue to the peripheral blood, rather than from de novo production ${ }^{13,14}$. Since $98 \%$ percent of lymphocytes resides in the lymphoid tissues, measurements in peripheral blood should be interpreted with care ${ }^{15}$. Indeed one could argue that with progressive HIV-1 infection, increasing viral load and decreasing $\mathrm{CD}^{+} \mathrm{T}$ cells, a larger fraction of both $\mathrm{CD}^{+}$and $\mathrm{CD} 8^{+} \mathrm{T}$ cells will be trapped in the infected and inflamed lymphoid tissues because of increasing cytokine levels and HIV-related immune activation ${ }^{16-19}$. Furthermore, as memory and naive cells have different recirculation and homing pathways, differ- 
Fig. 2 Representative FACScan images of one well-responding patient at baseline, week 6 and week 36 during follow-up. Depicted are CD4* and CD8 ${ }^{*}$ cells stained for CD45RA and CD62L. Percentages of cells are presented within the according quadrant, the corresponding CD4 ${ }^{+}$and CD8 ${ }^{+} \mathrm{T}$ cells counts are shown above the images.
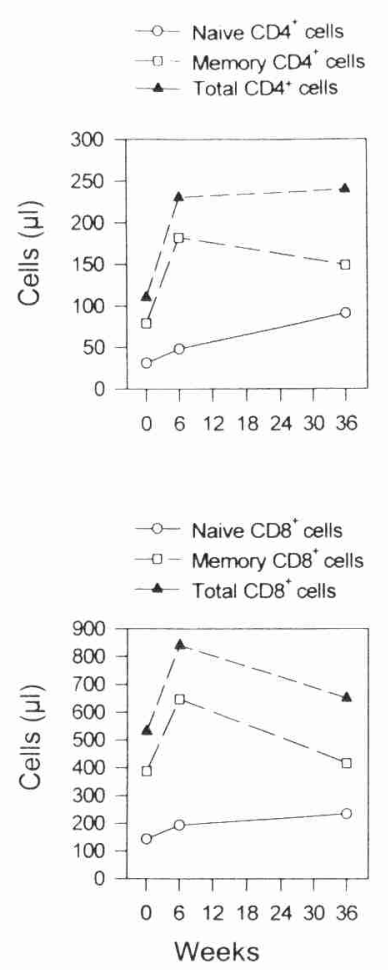

$\rightarrow-$ Naive CD8
$\rightarrow-$ cells
-4 Memory $C D 8^{+}$cells

« Total $\mathrm{CD}^{+}$cells

Weeks

CD4+ cells

Baseline

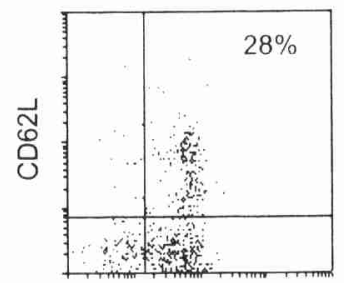

CD45RA

\section{CD8+ cells}

Baseline

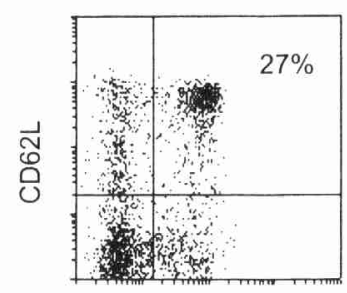

CD45RA
Week 6

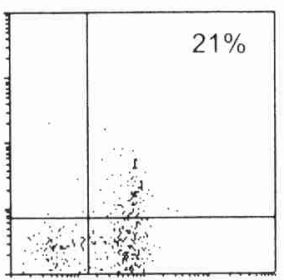

Week 6

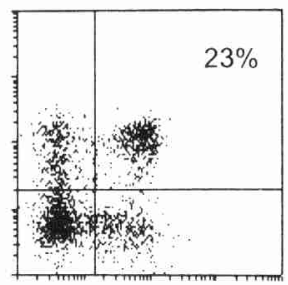

Week 36

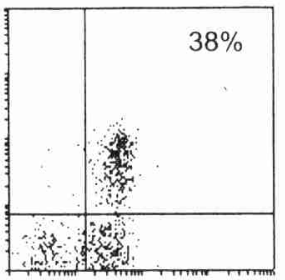

Week 36

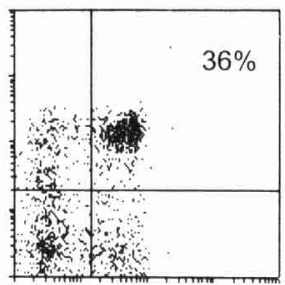

ences in sequestration of naive and memory $\mathrm{T}$ cells are to be expected $^{20}$. Once the viral load levels are strongly decreased by antiretroviral treatment, inflammatory responses will be reduced, cytokine levels will normalize and sequestered $\mathrm{T}$ cells will be released to the peripheral blood compartment. It is noteworthy that the apparently density-dependent growth indeed is also fully compatible with redistribution. As the magnitude of the memory $\mathrm{T}$-cell recovery in the peripheral blood should be proportional to the total number of memory T cells in the lymphoid tissue, we calculated for each patient a "fractional memory $\mathrm{T}$-cell recovery" $\Delta B / B$, where $\Delta B$ is the increase in memory cells during treatment and $B$ is the baseline peripheral blood memory T-cell count. Fig. 4, $c$ and $d$, depicts the fractional recovery of the CD $4^{+}$and CD $8^{+}$memory cells as a function of the total $\mathrm{CD}^{+}$baseline count. Like the density-dependent growth, the fractional recovery is inversely related to the baseline counts. Calculating the fractional $\mathrm{CD}^{+}$and $\mathrm{CD}^{+}$memory recovery one finds a strong correlation between these two parameters (Fig. 4e, $r=0.83$ ). blood and the lymphoid tissue, respectively, and $T$ as a "trapping factor," defined in terms of the lymphocytes that are trapped in the lymphoid tissue when $T>1$. As argued above this increased retention of lymphocytes $(T>1)$ is caused by virus-induced immune activation such as increased cytokine levels, which will decrease quickly following potent antiviral therapy. The total number of $\mathrm{CD}^{+} \mathrm{T}$ cells in the blood can be expressed as,

$$
B=\frac{L}{50 T}
$$

which in the absence of trapping $(T=1)$ says that $2 \%$ of the lymphocytes reside in the blood. If one argues that the rapid increase in peripheral CD4 ${ }^{+} \mathrm{T}$ cells during the first three weeks of treatment is entirely due to redistribution, that is, the loss of trapping, the difference in the peripheral blood $\mathrm{CD} 4^{+} \mathrm{T}$-cell count,

$$
\Delta B=\frac{L}{50}-\frac{L}{50 T}=\frac{L(T-1)}{50 T}
$$

is proportional to $L$, and is inversely proportional to $T$. This can

\section{Mathematical model for immunological recovery} By mathematical modeling we explored the idea of redistribution as the first immediate response of T cells in patients on highly active antiretroviral therapy, taking into account the two major lymphocyte compartments. We chose $B$ and $L$ as the total number of CD $4^{+} \mathrm{T}$ cells in the peripheral

Fig. 3 Kinetics of $\mathrm{CD}^{+}$and $\mathrm{CD} 8^{+}$naive and memory lymphocyte subpopulations. $\boldsymbol{a}$, Pattern of (absolute) mean response on therapy in the CD4+ $\mathrm{T}$-lymphocyte naive $(O)$ and memory $(\square)$ subset and the total CD4+ T-cell count $(\mathbf{\Delta})$. $\boldsymbol{b}$, Pattern of (absolute) mean response on therapy in the CD8* T-lymphocyte naive $(O)$ and memory $(\square)$ subset and the total CD8. T-cell count ( $)$. Bars represent s.e.m.
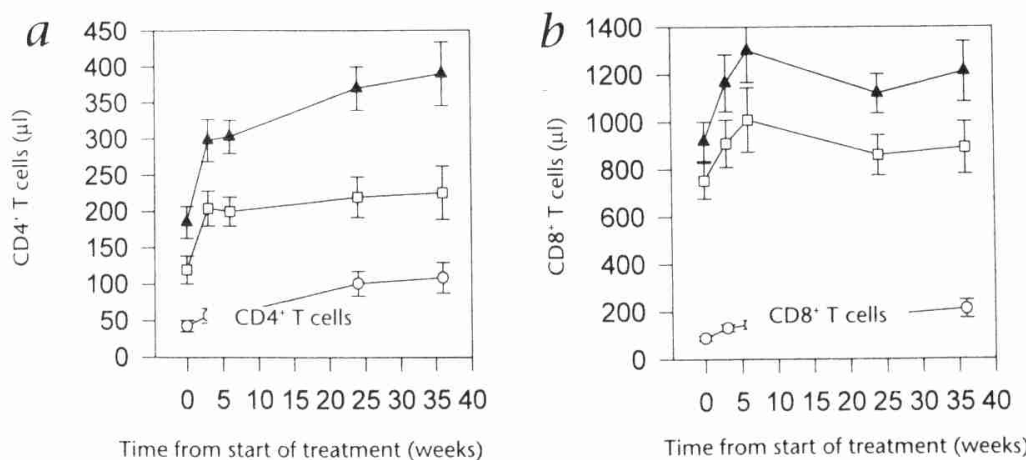

Time from start of treatment (weeks) 
Fig. 4 Individual $\mathrm{CD}^{+}$and CD8. $T$-cell increases as a function of the baseline total CD4 $4^{+} \mathrm{T}$. cell count. Depicted are the recovery rates after start with antiviral therapy during the first three weeks for $\mathrm{CD}^{*} \mathrm{~T}$ cells and during the first six weeks for CD8* $\mathrm{T}$-cell numbers. CD4 $4^{+}$and CD8 ${ }^{*}$ T-cell increases were expressed as the exponential rate of increase ( $a, b$, column 4 in Table 2 ) and as the fractional increase

( $c$ and $d$ ). In addition, the relation between the fractional increase of memory $\mathrm{CD4} 4^{+} \mathrm{T}$ cells and memory $\mathrm{CD} 8^{+} \mathrm{T}$ cells during the initial fast repopulation period after start with antiretroviral therapy is shown (e).

be simplified by calculating the relative increase of peripheral CD $4^{+} \mathrm{T}$ cells, that is, fractional increase, as,

$$
\Delta B / B=\frac{L(T-1)}{50 T} \times \frac{50 T}{L}=T-1
$$

According to this simple mathematical model, the fractional recovery $\triangle B / B$ in the peripheral blood is determined by the trapping factor $T$ only, reflecting the increased residence of $T$ cells in tissue. Thus if we assume redistribution, the model shows that fractional growth is directly related to the trapping factor $T$; the data demonstrate that there is an inverse relation between baseline $\mathrm{CD} 4^{+} \mathrm{T}$-cell count and increase in $\mathrm{CD} 4^{+} \mathrm{T}$ cells after therapy; from that we conclude that $T$ is apparently higher in patients with lower baseline $\mathrm{CD}^{+}$counts. Furthermore, trapping of CD $4^{+} \mathrm{T}$ cells in the lymphoid tissue is also significantly correlated with viral load levels at baseline ( $r$ $=0.65)$. The average fractional recovery for the CD $4^{+} \mathrm{T}$ cells was 1.2 and for the CD8 ${ }^{+} \mathrm{T}$ cells 0.6 . This results in trapping factors $T$ of 2.2 and 1.6 , respectively, meaning that instead of the normal $2 \%$, in these HIV-1-infected patients only about $1 \%$ of the $\mathrm{T}$ cells resides in the peripheral blood. Additionally, if we assume that a $70-\mathrm{kg}$ individual has 5 liters of blood, this would mean that the average $\mathrm{CD}^{+}{ }^{+} \mathrm{T}$-cell count of 120 cells $/ \mu \mathrm{l}$ blood before the onset of therapy corresponds to $6 \times 10^{10}$ memory CD4 $4^{+}$cells in the lymphoid tissue $\left(120 \times 5 \times 100 \times 10^{6}=6 \times\right.$ $10^{16}$ cells). This is in agreement with Zhang et al. ${ }^{21}$ who studied the immunological data of $\mathrm{CD}^{+}$repopulation in lymphoid tissues obtained for a subpopulation of the patients that are described in the present study. We argue that after the initial recovery period following antiviral therapy, a new steady state is approached with an approximately normal distribution of $2 \%$ of lymphocytes in the blood. This steady state corresponds to the ceiling in the memory $\mathrm{CD}^{+} \mathrm{T}$-cell number that is reached after 3 weeks and remains lower than normal, since total $\mathrm{CD} 4^{+} \mathrm{T}$ cells numbers in the body are still significantly decreased $^{21}$.

In summary, the biphasic CD4+ $\mathrm{T}$-cell kinetics, the finding that $\mathrm{CD}^{+}$memory $\mathrm{T}$ cells quickly reach a subnormal plateau, the similarities between the $\mathrm{CD}^{+}$and $\mathrm{CD}^{+}$T-cell repopulation in the blood, the improved CD8* recovery at low CD 4. counts and the strong correlation between the fractional CD4. and $\mathrm{CD}^{+}$recovery, all find a straightforward explanation in the redistribution model, but are not explained by the proliferation model. Obviously, we cannot rule out some contribution to the initial rise in peripheral blood CD $4^{+} \mathrm{T}$-cell numbers $b$

CD8. $T$ cells

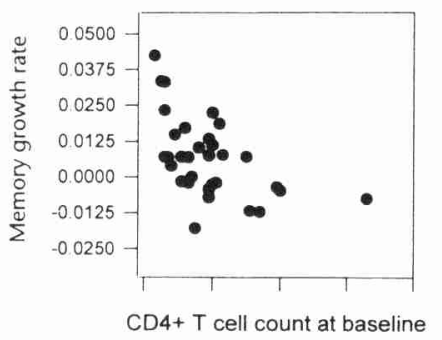

d

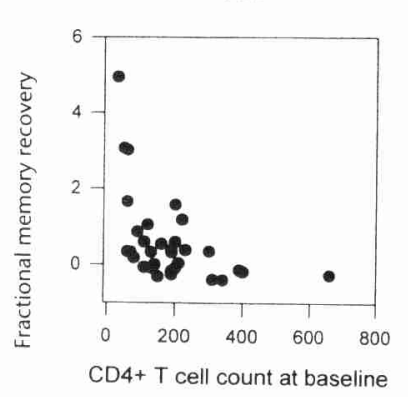

C

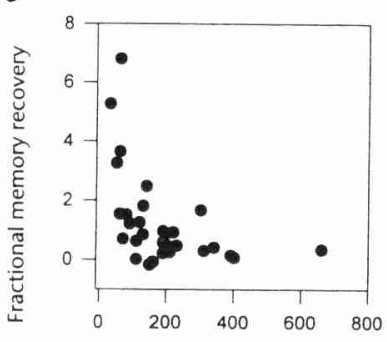

CD4 + T cell count at baseline of memory $\mathrm{CD}^{+} \mathrm{T}$-cell production. The daily production of naive $\mathrm{CD}^{+}$and $\mathrm{CD} 8^{+} \mathrm{T}$ cells does contribute to long-term total $\mathrm{T}$-cell repopulation and can be compatible with little changes in the $V \beta$ repertoire and CDR3 region in the first months of antiviral therapy ${ }^{22}$.

Altogether our results thus suggest that the initial rise in memory CD4+ $\mathrm{T}$ cells is not a reflection of high $\mathrm{CD} 4^{+} \mathrm{T}$-cell production levels before treatment. During the natural course of HIV-1 infection in patients with CD $4^{+} \mathrm{T}$-cell counts above 200 cells/ $\mu \mathrm{l}$, normal $\mathrm{CD}^{+}{ }^{+} \mathrm{T}$-cell telomere lengths ${ }^{23-25}$ and normal frequencies of HPRT mutations ${ }^{26}$ were found, which also argues against a markedly increased daily $\mathrm{CD}^{+}{ }^{+} \mathrm{T}$-cell production.

\section{Consequences for immune reconstitution}

Irrespective the mechanism that causes the initial steep increase in memory CD4+ T-cell counts after therapy, our data provide evidence that the long-term repopulation of newly produced naive CD4 ${ }^{+} \mathrm{T}$ cells is a much slower process than was generally anticipated ${ }^{5,6}$. Our calculated daily production rate of naive $\mathrm{CD} 4^{+} \mathrm{T}$ cells of $5.7 \times 10^{7}$ cells per day is in good agreement with the repopulation rate of naive CD $4^{+} \mathrm{T}$ cells in lymphoid tissues ${ }^{21}$ and approaches the estimates reported after chemotherapy in adults ${ }^{27}$. These authors showed that substantial repopulation of $\mathrm{CD}^{+} \mathrm{T}$ cells is mainly caused by an increase in CD45RA+ $\mathrm{T}$ cells and is only achieved after more than 12 months with an estimated CD $4^{+} \mathrm{T}$ cell increase on the order of $10^{8}$ cells per day. The same is observed in patients who received bone marrow transplantation or were transplanted with purified allogeneic peripheral stem cells ${ }^{28}$ and in multiple sclerosis patients that had been treated with a depleting CD4 monoclonal antibody ${ }^{29}$. Slow naive CD4 ${ }^{+} \mathrm{T}$ turnover is also compatible with the normal rate at which naive CD 4 ${ }^{+} \mathrm{T}$ cells lose their telomere length by cell division ${ }^{30}$ (R.J.deBoer. et al., manuscript submitted, K.C. Wolthers et al., manuscript submitted).

If the initial restoration of $\mathrm{CD}^{+} \mathrm{T}$-cell numbers in the blood is mainly due to redistribution of cells previously sequestered 
to lymphoid and inflamed tissues, one has to reinterpret this "repopulation" with respect to its contribution to the patient's immune reconstitution. In a recent paper Autran et al." showed a substantial improvement of antigen-specific responses by peripheral blood lymphocytes in the first three months following antiviral combination therapy. If this is merely caused by an increase in the number of CMV-and tuberculin-reactive $T$ cells in peripheral blood mononuclear cells (PBMCs) as a result of redistribution of memory $\mathrm{T}$ cells to the blood, it need not reflect a generalized immune reconstitution in the patients.

It has been shown before that a rise in CD $4^{+} \mathrm{T}$-cell numbers following therapy is a correlate of clinical benefit ${ }^{32-35}$. Qualitative T-cell functional improvement, which is known to be of prognostic relevance in HIV-1 infection ${ }^{36}$, has been observed in clinical trials ${ }^{37-39}$. Complete quantitative or qualitative reconstitution of the immune system may not be achieved or may take a long time to be achieved. It remains to be seen how the initial rapid distribution of memory cells, the gradual slow increase in naive $T$ cells or the functional improvement of $T$ cells contribute to immune reconstitution and long-term clinical response to antiviral combination therapy. We anticipate that the latter two may be most critical for successful immune restoration following therapy.

\section{Methods}

Lymphocyte counts and T-cell function. Patients were followed at weekly intervals between week -2 and 4 from the onset of therapy, with additional visits at day 3 and day 10, and at week 6, 8, and every four weeks thereafter. Whole blood collected in EDTA was analyzed by a whole-blood lysis technique. Lymphocyte immunophenotyping for peripheral $\mathrm{CD}^{+}$and $\mathrm{CD} 8{ }^{+} \mathrm{T}$ cells and $\mathrm{CD} 19^{+} \mathrm{B}$ cells was assessed by twocolor immunofluorescence flow cytometry with a fluorescence-activated cell sorter (FACScan, Becton Dickinson, San Jose, CA). Proliferative response to CD3 monoclonal antibodies (mAbs) was determined in wholeblood lymphocyte culture, as previously described in detail ${ }^{40}$. In short, proliferative capacity was measured by adding $\left[{ }^{3} \mathrm{H}\right]$ thymidine to the cultures at day 3. After a $24-\mathrm{h}$ incubation, the incorporation of $\left[{ }^{3} \mathrm{H}\right]$ thymidine was measured as counts per minute. Proliferative capacity was expressed per $10^{3} \mathrm{CD}^{+} \mathrm{T}$ cells using the absolute $\mathrm{CD} 4^{*}$ and $\mathrm{CD} 8^{+} \mathrm{T}$-cell count.

Naive and memory lymphocyte counts. Three-color flow cytometry was performed for supplemental T-lymphocyte subsets, expressing the surface proteins CD45RA, CD45RO and CD62L (L-selectin). A panel of mAbs to the following cell surface markers was used: fluorescein isothiocyanate (FITC)-conjugated CD62L, phycoerythrin (PE)-conjugated CD45RA and CD45RO, CD4 and CD8 PerCP. T-cell subsets expressing CD45RA and $\mathrm{CD} 62 \mathrm{~L}$ were regarded as truly naive $T$ cells, whereas $T$ cells expressing CD45RO, as well as T cells that express CD45RA but lack CD62L, were regarded as memory lymphocytes. Note that the sum of memory and naive cells is less than the absolute number of $T$ cells because of dull stained $T$ cells for CD45RA and CD45RO.

Viral RNA load. Plasma HIV-1 RNA levels were measured by a quantitative reverse-transcriptase polymerase chain reaction (RT-PCR) assay (Amplicor-HIV monitor test, Roche Molecular Systems, Branchburg, NJ) with a mean lower limit of quantification for this study of 251 copies $/ \mathrm{ml}$. Plasma RNA load levels were log-transformed, and cutoff values were assigned to measures below the assay's lower quantification limit ( $\log _{10} 251$ $=2.4 \log$ copies $/ \mathrm{ml}$ ).

Statistical analysis. Analyses were performed for the intention-to-treat population with no data exclusions. Patients withdrawn from study medication were followed until other antiretroviral treatment was started. Time-dependent analyses were performed using a repeated measurement model (Proc mixed, SAS 6.11) including baseline values, time since the start of treatment and therapy group as covariates. Immunological and vi- rological baseline values were calculated as the mean value of three measurements taken before treatment (week $-2,-1$ and 0 ).

\section{Acknowledgments}

We greatly acknowledge all colleagues for generating immunologic and virologic data, the physicians P. Meenhorst, N. Foudraine and R. Kauffmann and the study participants, and NATEC for support in coordinating the study. We thank R. van Lier, H. Schuitemaker, K. Wolthers, D. Clark, M. Klein and A. van ' $t$ Wout for critical reading the manuscript. This study was financially supported by Abbott Laboratories, by Claxo-Wellcome Research and Development, and by grants from the Netherlands Foundation for Preventive Medicine.

\section{RECEIVED 25 AUGUST; ACCEPTED 12 DECEMBER 1997}

1. Cavert, W. et al. Kinetics of response in lymphoid tissues to antiretroviral therapy of HIV-1 infection. Science 276, 960-964 (1997).

2. Lafeuillade, A., Poggi, C., Profizi, N., Tamalet, C. \& Costes, O. Human immunodeficiency virus type 1 kinetics in lymph nodes compared with plasma. I. Infect. Dis. 174, 404-407 (1996)

3. Perelson, A.S. et al. Decay characteristics of HIV-1 infected compartments during combination therapy. Nature 387, 188-191 (1997)

4. Notermans, D.W. et al. Decrease of HIV-1 RNA levels in lymphoid tissue and peripheral blood during treatment with ritonavir, lamivudine and zidovudine. AIDS (in the press).

5. Wei, $X$. et al. Viral dynamics in human immunodeficiency virus type 1 infection. Nature 373, 117-122 (1995).

6. Ho, D.D. et al. Rapid turnover of plasma virions and CD4 lymphocytes in HIV-1 infection. Nature 373, 123-126 (1995).

7. Kelleher, A.D., Carr, A., Zaunders, J. \& Cooper, D.A. Alterations in the immune response of human immunodeficiency virus (HIV) infected subjects treated with an HIV-specific protease inhibitor, ritonavir. I. Infect. Dis. 173, 321-329 (1996)

8. Picker, L.J. et al. Control of lymphocyte recirculation in man: Differential regulation of the peripheral lymph node homing receptor L-selectin on T cells during the virgin to memory cell transition. I. Immunol. 150, 1105-1121 (1993).

9. Roederer, M. et al. CD8 naive T cell counts decrease progressively in HIV infected adults. J. Clin. Invest. 95, 2061-2066 (1995)

10. Perelson, A.S., Neumann, A.U., Markowitz, M., Leonard, J.M. \& Ho, D.D. HIV-1 dynamics in vivo: Virion clearance rate, infected cell life-span, and viral generation time. Science 271, 1582-1586 (1996).

11. Tough, D.F. \& Sprent, J. Viruses and T cell turnover: Evidence for bystander proliferation. Immunol. Rev. 150,129-142 (1996).

12. Ahmed, R. \& Gray, D. Immunological memory and protective immunity: Understanding their relation. Science 272,54-60 (1996).

13. Mosier, D.E., Sprent, I., Tough, D., Dimitrov, D.S. \& Martin, M.A. HIV results in the frame: CD4 cell turnover (letter). Nature 375, 193-195 (1995).

14. Phillips, A.N., Sabin, C.A., Mocroft, A. \& Janossy, G. HIV results in the frame: Antiviral therapy (letter). Nature 375, 195 (1995).

15. Westermann, J. \& Pabst, R. Lymphocyte subsets in the blood: A diagnostic window on the lymphoid system? Immunol. Today 11, 406 (1990).

16. Butcher, E.C. \& Picker, L.J. Lymphocyte homing and homeostasis. Science $\mathbf{2 7 2}$ 60-66 (1996)

17. Pantaleo, G. et al. HIV infection is active and progressive in lymphoid tissue during the clinically latent stage of disease. Nature 362, 355-358 (1993).

18. Giorgi, I.V. Phenotype and function of T cells in HIV disease, in Immunology of HIV Infection. (ed. Gupta, S.) 181-199 (Plenum Press, New York, 1906).

19. Wang, L., Robb, C.W. \& Cloyd, M.W. HIV induces homing of resting T lympho cytes to lymph nodes. Virology 228, 141-152 (1997)

20. Gray, D. Immunological memory. Annu. Rev. Immunol. 11, 49-77 (1993)

21. Zhang, $Z$. et al. Naive CD4* $T$ cells repopulate lymphoid tissues after treatment of HIV-1 infection. Proc. Natl. Acad. Sci. USA (in the press)

22. Connors, M. et al. HIV infection induces changes in CD4. T-cell phenotype and depletions within the CD4. T-cell repertoire that are not immediately restored by antiviral or immune-based therapies. Nature Med. 3, 533-540 (1997).

23. Wolthers, K.C. et al. T-cell telomere length in HIV-1 infection: No evidence for in creased CD4+ T cell turnover. Science 274, 1543-1547 (1996).

24. Pommier, J.-P. et al. Immunosenescence in HIV pathogenesis. Virology 231 , $148-154$ (1997).

25. Palmer, L.D. et al. Telomere length, telomerase activity, and replicative potential in HIV infection: Analysis of CD $4^{\circ}$ and CD $8^{\circ} \mathrm{T}$ cells from HIV-discordant monozygotic twins. J. Exp. Med. 185, 1381-1386 (1997).

26. Paganin, C., Monos, D.S., Marshall, J.D., Frank, I. \& Trinchieri, G. Frequency and cytokine profile of HPRT mutant T cells in HIV-infected and healthy donors Implications for T cell proliferation in HIV disease. 1. Clin. Invest. 99, 663-667 (1997).

27. Mackall, C.L. et al. Age, thymopoiesis, and CD4* T-lymphocyte regeneration after intensive chemotherapy. N. Engl. I. Med. 332, 143-149 (1995)

28. Ottinger, H.D., Beelen, D.W., Scheulen, B., Schaefer, U.W. \& Gross-Wilde, H. Im proved immune reconstitution after allotransplantation of peripheral blood stem cells instead of bone marrow. Blood 88, 2775-2779 (1996). 
29. Rep, M. et al. Treatment with depleting CD4 monoclonal antibody results in a preferential loss of circulating naive $T$ cells but does not affect IFN- $\tau$ secreting TH1 cells in humans. 1. Clin. Invest. 99, 2225-2231 (1997).

30. Weng, N.-P., Levine, B.L., June, C.H. \& Hodes, R.J. Human naive and memory T lymphocytes differ in telomeric length and replicative potential. Proc. Natl. Acad. Sci. USA 92,11091-11094 (1995).

31. Autran, B. et al. Positive effects of combined antiretroviral therapy on CD4. T cell homeostasis and function in advanced HIV disease. Science 277, 112-116 (1997).

32. Hammer, S.M. et al. A trial comparing nucleoside monotherapy with combina tion therapy in HIV-infected adults with CD4 cell counts from 200 to 500 per cubic millimeter. N. Engl. J. Med. 335, 1081-1090 (1996).

33. Katzenstein, D.A. et al. The relation of virologic and immunologic markers to clinical outcomes after nucleoside therapy in HIV-infected adults with 200 to 500 CD4 cells per cubic millimeter. N. Engl. I. Med. 335, 1091-1098 (1996).

34. Delta Coordinating Committee. Delta: A randomised double-blind controlled trial comparing combinations of zidovudine plus didanosine or zalcitabine with zidovudine alone in HIV-infected individuals. Lancet 348, 283-291 (1996).

35. O'Brien, W.A. et al. Changes in plasma HIV RNA levels and CD4* lymphocyte counts predict both response to antiretroviral therapy and therapeutic failure.
Ann. Intern. Med 126, 939-945 (1997)

36. Roos, M.T.L. et al. T-cell function in vitro is an independent progression marker for AIDS in human immunodeficiency virus (HIV)-infected asymptomatic individuals. J. Infect. Dis. 171, 531-536 (1995).

37. Koot, M. et al. Viral phenotype and T-cell reactivity in human immunodeficiency virus type 1 -infected asymptomatic men treated with zidovudine. I. Infect. Dis. $168,733-736$ (1993).

38. Bindels, P.J.E. et al. The predictive value of $T$ cell function in vitro and pre AIDS zidovudine use for survival after AIDS diagnosis in a cohort of homosexual men in Amsterdam. J. Infect. Dis. 172, 97-104 (1995).

39. Pakker, N.G. et al. Patterns of $T$ cell repopulation, viral load reduction and restoration of $\mathrm{T}$ cell function in human immunodeficiency virus infected persons during therapy with different antiretrovirals. I. Acquire. Immune Defic. Syndr. Hum. Retrovirol. 16, 318-326 (1997).

40. Bloemena, E., Roos, M.T.L., van Heijst, I.L.A.M., Vossen, I.M.J.I. \& Schellekens, P.T.A. Whole-blood lymphocyte cultures. I. Immunol. Methods 122, 161-167 (1989).

41. 1993 revised classification system for HIV infection and expanded surveillance case definition for AIDS among adolescents and adults. MMWR Morbid. Mortal. Wkly. Rep. 41, 1 (1992). 